\title{
A Study about Management and Business Issues of Ecommerce
}

\author{
*VASHUNDHRA SHARMA \\ * P.hd Scholar, Jiwaji University, Gwalior (M.P.)
}

\begin{abstract}
Electronic Commerce is the execution of business processes using Internet technologies continues to be a significant, pervasive issue for both enterprises and customers. Management of relationships between enterprises and customers has often been referred to as Customer Relationship Management (CRM). This paper considers such challenges, linked to the consumer's understanding and the usability of the security features. electronic business brings about profound impacts on a country's taxation system, taxation policy and taxation methods as well. In this paper we study about B2B ecommerce and B2C ecommerce.
\end{abstract}

Keywords - eCommerce, security, threats, B2B ecommerce, B2C commerce, taxation policy

\section{Introduction}

Electronic commerce is an unconventional market economy that is based on the sophisticated Internet technology. Electronic-commerce, emerging with the development of Internet technology, is business activities utilizing the computer hardware, software and network infrastructure connected in certain agreement. More and more traditional enterprises come to believe that the new economy with the characteristics of internalization, intellectual management and globalization is inevitable trend, and so is e-commerce.

\section{Objective of Electronic Business}

1) Electronic commerce is an economy with universal participants.

2) Electronic commerce is conducted electronically and paper-savingly.

3) Electronic commerce is a direct economy. Electronic business can cut down some middle transaction formalities.

4) Electronic commerce is an economy of rapidity.

5) Electronic commerce is an economy of fast growth.

6) Electronic commerce is an economy with low operation cost.

7) Electronic commerce is a competitive market economy.

\section{Security Challenges in Consumer-Oriented eCommerce}

The emergence of consumer-oriented electronic commerce is one of the recognised successes of the Internet in recent years. It is now possible to buy almost anything on the net that can be found in traditional bricks and mortar shops, and online sales are on the increase. In considering how people might protect themselves from risks, we should not underestimate the level of technology awareness that an end user really needs in order to be a safe eConsumer. Although the largest volume and value of transactions occur in the business-to-business (B2B) .it can be argued that the most challenging security issues are encountered in the scenarios that involve consumers. Whereas organizations engaging in B2B transactions can reasonably be expectedtopossesssomelevel $\mathrm{f}$ competent IT support (and potentially even in-house security expertise), this is far less likely to be guaranteed when dealing with the end-user community in a business-to-consumer (B2C) scenario. As such, there are two potentially problematic issues for users when placed in an eCommerce scenario:-

- The need to recognize the threats.

- The need to use the technology securely.

\section{Understanding The Threats}

When considering the potential threats relating to ecommerce, a key issue is that consumers' lack of knowledge of how services are meant to work can render them susceptible to a variety of tricks and deceptions. Good examples here are phishing and pharming attacks, which attempt to dupe the user into divulging sensitive information such as credit card numbers, bank account details, passwords and the like. Both forms of attack work by hijacking well known brands that the user is likely to trust, and using this trust as the basis for convincing them to part with the desired information. Phishing attempts are typically initiated via email, with the user being sent a fake message. 


\section{Understanding The Technology}

Whether they fully understand the threats or not, many users will still recognize a requirement for security in an eCommerce scenario. As such, they will accept the need for associated technology measures to be used to provide safeguards. However, it is important to consider what they actually understand about the security they need or the protection they are receiving.

\section{Accessibility and Scalability in Collaborative ecommerce Environments}

ecommerce applications have increased at a large rate. Almost every major shop (e.g. Best Buy, IKEA, etc.) now has an ecommerce-enabled website displaying the products it sells in real-life. Most of the present commercial ecommerce systems resemble catalogues through which customers browse, trying to emulate reallife shopping experience. These schemes often consist of product specifications and few pictures, reducing the quality of customers' experience. Shopping in real-life has other components attached to it: Customers consult with each other and with experts about products and usually shop in groups benefiting from each others' experiences and opinions. These aspects, when lacking, can lead to reduction in sales. We therefore argue to combine the virtual market with a social place, where the customers participate in should change their role: from consumers to people, who want to satisfy their wide range of needs through shopping. The purchase of goods is only one of them; social interaction, learning, or excitements are others. To mitigate this problem, we proposed the idea of Collaborative Virtual Environments (CVE) in a web oriented system . With the creation of a virtual shopping mall, simulations of the actual shopping environments and user interactions can be achieved to a great extent. systems have many design aspects, there are two major concerns in their design and implementation: accessibility and scalability. Accessibility, according to the World Wide Web Consortium, is mostly targeted towards allowing people with disabilities to browse the internet easily, accessibility usually refers to the extent a web page can be viewed by the maximum number of people without enduring some modification, generally in terms of downloadable plug-ins or, less frequently, assistive devices.VR-based ecommerce systems require VRML or Java 3D plug-ins

\section{Electronic Customer Relationship Management}

Electronic Commerce (ecommerce, i.e. the execution of business processes using Internet technologies) continues to be a significant, pervasive issue for both enterprises and customers.Management of relationships between enterprises and customers has often been referred to as Customer Relationship Management (CRM). We define CRM as an interactive process that achieves an optimum balance between corporate investments and the satisfaction of customer needs to generate the maximum profit. Fundamentally CRM concerns attracting and keeping "economically valuable" customers and repelling and eliminating "economically invaluable" ones. The amount of information relevant in CRM processes can only be handled effectively when information technology is applied. Due to the lack of personal contact, CRM is of particular importance in eCommerce.

\section{Customer Experience Embedded In Marketing}

Marketing is a key management discipline that enables the producers of goods and services to interpret customers' wants, needs and desires, and then match them in delivery to their target customers. Primarily, one major goal of marketing is to create strong relationships between a company and its customers. Good customer experience can further create an intense feeling of loyalty toward the company and its products or services. According to Schneider, a five-stage model of customer loyalty has been applied by researchers to identify the customer life cycle as customer relationships develop over time.

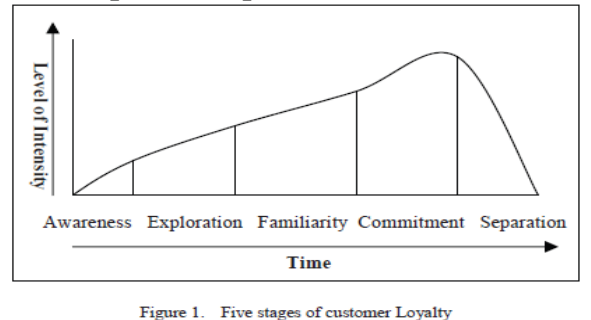

\section{A. Stage 1: Awareness}

Customers simply note the name or product of the company, but haven't had any interaction with the company at the initial phase. Brand advertising is frequently used to inform the potential customers of the goods and services.

\section{B. Stage 2: Exploration}

Prospective customers begin to care about the company or its products, and then show great initiative in communicating with the company to learn more about the product information. At this stage, a large amount of information interchange can take place between the parties. 


\section{Stage 3: Familiarity}

Having already completed several transactions with the company, existing customers are familiar with the concrete process of purchasing, even the policies concerning refund, warranty and pricing flexibility. However, they are still likely to shop and buy from other competitors occasionally.

\section{Stage 4: Commitment}

Being highly satisfied with the products or services, some customers cultivate an intense loyalty or preference for the brand of the company. These customers would like to broadcast their trustworthy experience. Most consumers, who have established close relationship with the products, are inclined to excitedly share their purchasing stories and try to persuade others.

\section{E. Stage 5: Separation}

Over time, the customers may be severely disappointed by changes in the level of service or product quality. At this point, the intensity of the relationship fades and ends gradually. In the light of the abovementioned model, a crucial objective of any marketing strategy ought to convert customers into the evangelists as quickly as possible and retain them as long as possible. Based on the five-stage model, the companies can create the life-cycle segmentation, which refers to the acquisition, conversion and retention of customers. Consequently, better customer experience can pave the way for the marketing among those target customers.

\section{Technology Of Ecommerce}

\section{B2C eCommerce :-}

The ecommerce began with the introduction of EDI between companies, and ATMs for banking .Introduction of the Web Browsers opened up a new age by combining open internet and easy user interface approaches . B2C ecommerce is the predominant commercial experience of Web users. A typical scenario involves a user's visiting one or several online shops, browsing their offers, selecting and ordering products. Ideally, a user would collect information about price, terms, and conditions (such as availability) of all or at least all major, online shops and then proceed to select the best offer. But manual browsing is too time-consuming to be conducted on this scale. Typically a user will visit one or a very few online stores before making a decision. However, the evolution of B2C ecommerce has been formed through various generations. Last models of B2C ecommerce are comparative shopping catalogs. Models such as pricescan.com that visit several shops, extract product and price information, and compile a market overview. The comparative result obtained is then displayed in a tabular format in the user's browser. This approach suffers from several drawbacks. First, it's necessary for these models to get access grant from vendors before to access their databases for retrieving any information. Since some vendors may not give access grant to their databases, their product information will not appear in the information provided by these models. We have proposed a Knowledge-based approach to resolve this problem . In this approach, products and price information are understood and extracted from Web pages of vendors' sites to build virtual catalog directly. Second, user still needs to face inconsistent user interfaces when he is linked from the comparison site to the actual purchasing site for shopping. Therefore, user has to learn logics of each site's user interface. For example, user has to analyze his question into some keywords based on logics of user interface and give them to the system. It means that there is not such a possibility that user can ask his question in form of natural language (such as English) and get his answer. We can say that using keywords based on logics of third generation system's user interfaces is not a good way to establish relationship between user and system . Because at first a user is not interested to extract keywords of his question or maybe he is unable to do so. On the other hand, usually a few keywords cannot cover the complete meaning of user's question. In most cases, users are searching clear responses for their questions, while the outputs of third generation systems are collection of answers related to user's question that probably they contain the correct answer. In recent years, Question Answering (QA) systems have evolved out of the field of Information Retrieval to meet better the needs of information seekers. Unlike simple keyword-based information retrieval systems, they aim to communicate directly with users through a natural language. They accept natural language questions and return exact answers eliminating the burden of query formulation and reading lots of irrelevant documents to attain the answer.

\section{B2B ecommerce :-}

B2B-related technology implementations in the form of Electronic Data Interchange (EDI) were first initiated around 1986-7 by a number of large companies which included the major retailer Coles-

Myer, Ford automotive, Australian Paper Manufacturing (APM), BHP Steel, the Australian Customs Service (ACS) and the Australian Quarantine and Inspection Service (AQIS). EDI adoption have revealed that fundamental factors, such as lack of awareness of the benefits of EDI and lack of willing trading partners, are still contributing to the slow adoption of EDI in Australia. Other reasons suggested by these authors include the higher implementation costs associated with the establishment and on-going communication costs (eg. VANrelated charges) The introduction of the Internet for commercial use in the mid 1990s has offered a solution to this cost associated problem. Using the Internet as the communications medium for EDI transactions these costs, 
which include the cost of purchasing the translator software, the establishment of the communications network or subscription to a value-added network can all be reduced. the most popular B2B eCommerce applications used by organisations are:-

1. Traditional electronic data interchange (EDI), which is the exchange of formatted electronic documents between organisations using an agreed standard. Various forms of traditional EDI include proprietary file exchange, VAN-based or direct link EDI, and EDI to fax.

2. Internet EDI, which is EDI formatted documents transmitted over the Internet (eg. the use of file transfer protocol (FTP) or email applications to place the EDI messages into formatted documents and transmit them to their intended recipients);

3. Web-forms, which is the use of a web-based form or web intelligent interactive form to exchange business documents over the Internet. This included various organization's specific document transmissions and exchanges;

4. XML EDI, which is the Internet-based EDI featuring interactive business document exchange,

has been predicted to be the next mostly used ecommerce for the B2B ecommerce. Although this technology has not been widely used in Australia, Tradegate/ECA, which is the Australian ecommerce peak body, has stepped into this initiative by working with a number of Australian industries towards the development of the international XML standard proposed by the United Nations: ebXML. This initiative aims to lower the entry barriers to electronic business for mall and medium-sized enterprises (SMEs).

5. Other varieties of purely Internet/web-based initiatives such as procurement solution and emarketplaces,and B2B portals. This type of initiative is often implemented without any reference to EDI as in 1-3. According to Forrester research this year, there were about 2500 such initiatives.

\section{The Impact of E-commerce on Taxation System}

The electronic business brings about profound impacts on a country's taxation system, taxation policy and taxation methods as well. The influences of electronic commerce on the taxation system include, but are not limited to those listed below.

1) Electronic business shakes the foundation of the traditional taxation system for which voucher audit is the basis. So many order and mail services of electronic business are fulfilled on the Internet while the transaction records are modifiable information data. Thus, the transaction process of sell and purchase is complicated because of the impalpable information transaction.

2) The computer encryption techniques increase the difficulty for the taxation department to obtain the concerning information. The taxpayer can intently conceal the concerning electronic information of their business activities through the usage of computer encryption technique that is cost-consuming for taxation department to collect the necessary information.

3) It is difficult to make certain the standing body of the business dealers. According to most taxation agreements, one of the preconditions that one country can impose tax on an enterprise's business profit is that the proprietor must have the standing body in the country concerned. It is obvious that the concept of traditional standing body includes two aspects, that is, people and material. While a large number of citizens who can carry out business activities through the computer servers at the origin country, it arouses arguments whether the computer servers can serve as one of the standing body.

4) Electronic commerce underlies the conflict of taxation jurisdiction between related countries. In general, it is the management center or control center as the principle for every country to judge the identity of artificial person. However, with the emergence of electronic business and the widely used advanced technology, it is likely for the management center of an enterprise to be in any country in such an integrated international trade environment. Under these circumstances, taxation department feels it difficult to levy income tax on enterprises in accordance with the jurisdiction principle of citizen location that is more a nominal principle than a real one. 5) It is hard to cognize the product qualification and the product transfer price. It is difficult to differ commodity, service from franchise in electronic business. Thereafter, it is impossible to collect the corresponding tax rate.

6) Electronic commerce greatly influents the prevailing taxation system. China's taxation system as well as that of other countries' is established on the basis of supervision on the buyers and sellers. It is costly for the present taxation system to successfully manage those transactions of such a large volume in such a special business environment.

7) The international tax aversion becomes more and more serious. Due to the various tax rates between different countries, it is possible to make use of the websites in countries which implement tax exemption or low tax policies so as to avoid tax payment. 


\section{The role of people in the e-commerce world}

$\mathrm{n}$ the mass automation future, documents will be produced automatically by AI based information processing, machines have displaced people in factories, offices, banks, and shops. After all, a Big Mac can easily be dispensed of a vending machine. Where do people fit in?

When people watch TV, it transports them somewhere that they can watch people (or ccasionally animals). When people use telephones, or the Internet, it is mostly as communication with other people. Even searches for information are mostly just searches for the contents of someone else's mind. Chat areas are already becoming much more popular, but will evolve to include audio and video. These allow a more direct form of communication, rather than just via documents. The simple fact is that people themselves are content. Technology changes rapidly, but our socialization needs are still basically the same as when we were huntergatherers. When we have mass automation of industrial and information work, we will see the emergence of the care economy. Whatever is left that can only be offered by humans will account for an ever increasing share of the purchase price. A Big Mac may be dispensed by a vending machine, but you will pay extra in another restaurant for the French waiter to sneer down his nose when you choose an unsuitable wine. Washing out a bedpan may be automated, but compassion is a specist thing, dispensed best by a friendly, cuddly nurse. Undoubtedly, this will change as we come to accept the eventual validity of advanced synthetic intelligence, but it will take time to adjust. We will prefer people to machines in many situations and for many roles for many years.

This will affect e-commerce significantly. If it were not for the social, interpersonal side of shopping, people could be completely replaced by automated systems. But shopping is a social experience much of the time. Cyberspace can allow us to take our friends with us or meet them there. We can all share the same virtual environments. But the people are an important part of this, and they can't all be replaced. Many will be replaced, but the rest will reinvent their role,concentrating on the interpersonal value-add aspects, instead of the transaction processing. We may see the same need strongly affecting the nature of the machines. Machines will do many things, but their human interfaces will often have human-like characteristics, appearance, behaviour, emotions and so on. It may be quite common to base machine interfaces on digitally reconstructed emulations of real people, using digital actors and so on. Of course, their digitalimages and behaviours can be cosmetically enhanced as appropriate. The sci-fi film 'Looker' may be quite close to future reality. Future agents in eshopping may look like our familiar actors and actresses, cartoon characters, aliens or droids.

\section{Conclusions}

E-commerce is much more than just ordinary commerce with electronic cash. It will ultimately have far reaching consequences for our whole economic, social and political structures. By reducing the restrictions of geography, it will make commerce much more global, and as a second order effect, will force reform of monetary and taxation systems.

The power of banks will be greatly reduced as cash can be held and managed just as easily by its owners. Similarly, shopping will evolve to use the best of electronic commerce, physical outlets and mass customization, with a greatly improved distribution infrastructure. As many jobs are automated, we will see the rise of the care economy, with more focus on the human interaction side of jobs. But by then, even our interfaces to machines will look human.

\section{References}

[1]. D.Chaffey, E-Business and E-Commerce Management: Strategy,Implementation and Practice. Financial Times / Prentice Hall, 2001.

[2]. Shen, Shirmohammadi, Desmarais, Georganas, Kerr, "Enhancing e-Commerce with Intelligent Agents in Collaborative eCommunities" EEEConference on Enterprise Computing, E-Commerce and EServices,San Francisco, CA, U.S.A, IEEE, June 2006.

[3]. Keen, P., et al., Electronic Commerce Relationships - Trust by Design. 2000, Upper Sadle River, NJ: Prentice Hall.

[4]. R. Kalakota, A. B. Whinston, Electronic Commerce, A Manager's Guide, 1st ed., Addison Wesley Professional, 1997,

[5]. Aïmeur, Esma; Brassard, Gilles; Fernandez, José M. and Mani Onana,"A privacy-preserving recommender system for electronic commerce,’'International Journal of Information Security, v 7, n 5, 2008.

[6]. Zheng Dafu, "Taxation policy under e-commerce", Contemporary Economics, n 11, 2008.

[7]. Timmers, Electronic Commerce: Strategies and Models for Business to Business Trading. 1999, Chichester: Wiley.

[8]. Hackney, Ray, "E-Business Strategies: The Nature of Customer Attention." Journal of Global Information Management, 2005,

[9]. Schneider, Gary P, Electronic Commerce. USA: Course Technology, 2003,

[10]. Turban, E., et al., Electronic Commerce: A Managerial Perspective. 2002, Upper Saddle River: Prentice Hall.

[11]. Tian Zhiyong, and Wang Yu.The Strategic Analysis of the Mass Customization Marketing. Value Engineering ,No.4, 2007 